\title{
EFFeCt OF Direct Metal LASER Sintering Process Parameters on Dimensional AcCuracy of AlSi10Mg Parts
}

\section{Hulusi Bugra Bagci, Binnur Sagbas \& M. Numan Durakbasa}

Abstract: Additive manufacturing (AM) is a rapidly growing technology that provides opportunity to generate complex geometries, layer-by-layer without any tool, die and fixture. AM was used just for rapid prototyping at first while it has been started to use for generating near net shaped final product in these days. However, dimensional accuracy is not at the desired level for the functional parts. Type of the AM method and process parameters have important effect on dimensional deviations of the AM parts. In this research study it is aimed to determine effect of process parameters on dimensional accuracy of AlSilOMg screw parts manufactured by Direct Metal Laser Sintering (DMLS) method. Taguchi L9 orthogonal array was used for experimental design. Laser power, scan speed, beam offset and build angle process parameters were changed in three different levels. Dimensional measurements were taken by coordinate measuring machine (CMM). Results were revealed that, process parameters had important effects on dimensional accuracy of DMLS manufactured parts.

Key words: Additive Manufacturing (AM); Direct Metal Laser Sintering (DMLS); AlSilOMg; dimensional accuracy
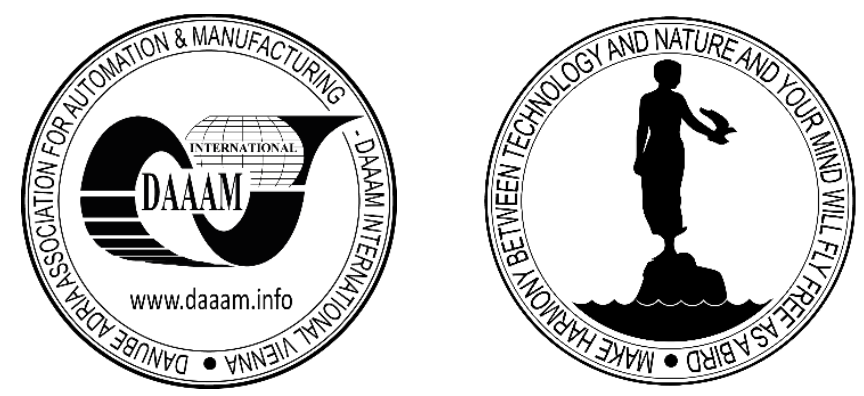

Authors' data: MSc. Student Hulusi Bugra Bagci*; Asst.Prof.Dr. Binnur Sagbas*, Professor Dr. techn. Prof.h.c. Dr.h.c. M. Numan Durakbasa**, *Yildiz Technical University, 34349 Besiktas Istanbul Turkey, **Vienna University of Technology, Getreidemarkt 9/311, A-1060, Vienna, Austria, bugra.bagci.26@gmail.com, bsagbas@gmail.com, numan.durakbasa@tuwien.ac.at

This Publication has to be referred as: Bagci, H[ulusi] B[ugra]; Sagbas, B[innur] \& Durakbasa, N[uman] (2020). Effect of Direct Metal Laser Sintering Process Parameters on Dimensional Accuracy of AlSi10Mg Parts, Chapter 13 in DAAAM International Scientific Book 2020, pp.171-180, B. Katalinic (Ed.), Published by DAAAM International, ISBN 978-3-902734-27-3, ISSN 1726-9687, Vienna, Austria DOI: $10.2507 /$ daaam.scibook.2020.13 
Bagci, H. B.; Sagbas, B. \& Durakbasa, N.: Effect of Direct Metal Laser Sintering P...

\section{Introduction}

Additive manufacturing (AM) has been a rapidly growing non-traditional manufacturing technology in recent years. AM technologies based on putting powder or wire material layer by layer until getting a solid object from 3D-CAD data. (Sağbaş, 2020) (Mohammadi \& Asgari, 2017) (Jhavar \& Jain, 2014). Capability of producing complex geometries, which is difficult with traditional methods, is one of the main advantages (Bhardwaj \& Shukla, 2018). Direct Metal Laser Sintering (DMLS) is an AM method that uses metal powders for raw materials and laser source for sintering. (Hanz et. Al., 2017). Although it has been used for near net shaped functional parts, dimensional accuracy is still need to be improved. Previous researches have shown that DMLS process parameters such as laser power, scan speed, hatch distance and build angle have important effect on geometric product specifications and mechanical properties of the products. Some researches focused on determining different parameter sets for increasing dimensional accuracy of the products however optimum process parameters have not been defined yet (Majeed et. al., 2019) (Rautio et. al., 2019).

AlSi10Mg has good mechanical properties, heat conductivity and improved corrosion resistance. Moreover, it is lightweight. That is why AlSi10Mg is widely used with AM applications especially in automotive and aerospace industries (Sagbas, 2019). Mamoon et al. researched the effect of process parameters on AlSi10Mg and Al6061 materials. Their study have shown that energy density is an important parameter which is related with laser power, scan speed and hatch distance. 8 specimens were produced when the energy density for AlSi10Mg material ranged from $27-65 \mathrm{~J} / \mathrm{mm}^{3}$. Best surface roughness was $4.5 \mu \mathrm{m}$ at maximum of energy density $65 \mathrm{~J} / \mathrm{mm}^{3}$ (Maamoon et. al., 2018). Scan strategy also have a significant role on density and micro-hardness. Scanning strategy studied by Tarun Bhardwaj et al. It turns out that the scanning direction has some effect on the density. Furthermore one-way scanned samples surface roughness almost 2 times higher than $X Y$ scanned parts. This is due to the existence of voids and cracks in one-way scanning more than XY scanning. XY scanning strategy is recommended for high quality finished parts. Also post-processing have improved surface quality (Bhardwaj \& Shukla, 2018). Han et al, studied about surface roughness and dimensional accuracy of SLMed parts. Their study focused on 2 parameters; hatch distance and scanning speed. When the hatch distance was fixed, there was an inflection point, which was defined $v_{c}$, dimensional accuracy depends on that inflection point. They reported that when the scanning speed lower than $v_{c}$, dimensional accuracy increases significantly with increasing scanning speed. However, when the scanning speed higher than $v_{c}$, dimensional accuracy nearly continual with the increasing scanning speed. Also better dimensional accuracy can be achieved with high scanning speeds on slant scanning (Han et. al., 2018).

Sing et al. mentioned about strut dimensions of lattice structures. Experiment parameters was, 400, 800, $1200 \mathrm{~mm} / \mathrm{s}$ for scanning speed, 120, 240 and $360 \mathrm{~W}$ for laser power and $0.03,0.05$ and $0.10 \mathrm{~mm}$ for layer thickness. Experiments have shown that, 
laser power was the most effective parameter for SLM produced parts rather than laser power or layer thickness. They concluded that for having better dimensional accuracy, laser power should be controlled (Sing et al., 2018). In another study Ghani et al. studied comparison between dimensional accuracy of SLM and DMLS manufactured parts. They reported that, SLMed parts had more dimensional deviations, which was \%5.12, than DMLSed parts, which was \%2.88 (Ghani et al., 2017). Gajera et al. aimed optimizing process parameters of DMLS produced parts. They revealed that surface roughness had significant effects on dimensional accuracy (Gajera et al., 2019).

In this study it is aimed to determine the optimal process parameters for improving dimensional accuracy of DMLSed AlSi10Mg parts. Four different process parameters such as scanning speed, laser power, beam offset and build angle were used with three different level. The parameter sets that were not used in previous studies were created and their effects on dimensional accuracy were evaluated by Taguchi's experimental design.

\section{Materials and Methods}

Screw shaped samples were designed for determining effect of process parameters on functional parts for end users. AlSi10Mg alloy samples were manufactured by EOS M290 DMLS system by $400 \mathrm{~W}$ Yb-fibre laser under argon atmosphere. AlSi10Mg powders were provided by EOS which were produced by gas atomization method. The medium size of the powder was about $30 \mu \mathrm{m}$. SEM image of the powder and CAD data of the screw sample can be seen in Fig. 1 while the chemical composition was given in Tab. 1 as stated by the producer in its data sheets.

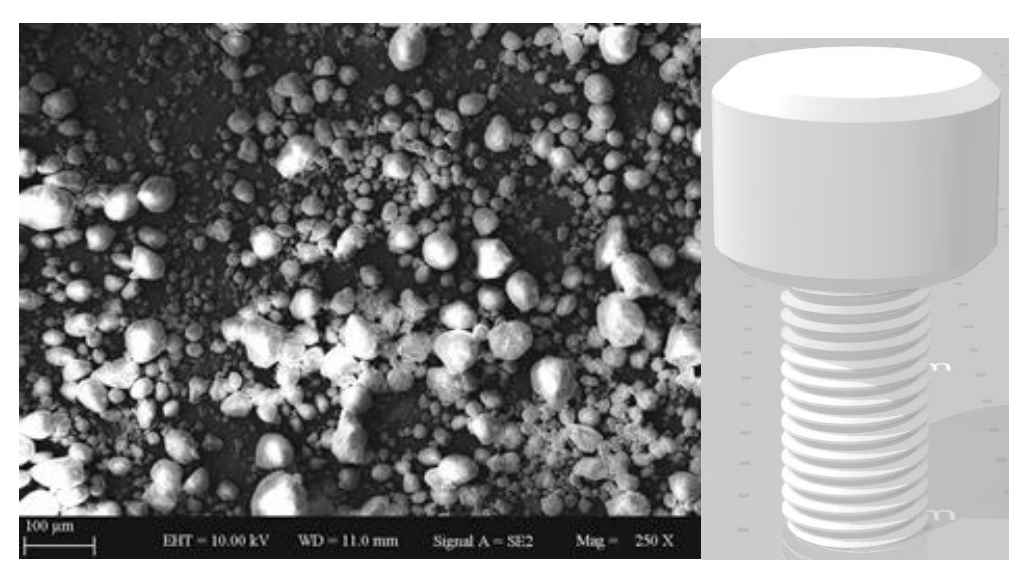

Fig. 1. SEM image of the AlSilOMg powder and CAD data of screw sample

\begin{tabular}{|c|c|c|c|c|c|c|c|c|c|c|}
\hline Al & Si (\%) & Fe & Cu & Mn & Mg & Ni & Zn & Pb & Sn & Ti \\
\hline Balance & $9.0-11.0$ & 0.55 & 0.05 & 0.45 & $0.2-0.45$ & 0.05 & 0.10 & 0.05 & 0.05 & 0.15 \\
\hline
\end{tabular}

Tab. 1. Chemical composition of AlSi10Mg

In the literature studies it has been reported that there are many parameters affecting the geometrical product specifications of DMLS manufactured parts as stated in the 
Bagci, H. B.; Sagbas, B. \& Durakbasa, N.: Effect of Direct Metal Laser Sintering P...

introduction part. In this study, laser power, scanning speed, beam offset and build angle process parameters were used at 3 different levels which were not experienced with these combinations. Because it would be extremely costly to try all combinations of each parameter set to determine optimal combination, Taguchi's experimental design technique was used. The parameters and levels of the 9 experimental sets created using Taguchi's L9 orthogonal experimental design model which can be seen in Tab. 2 below.

\begin{tabular}{|c|c|c|c|c|}
\hline Sample No & $\begin{array}{c}\text { Laser Power } \\
(\mathbf{W})\end{array}$ & $\begin{array}{c}\text { Scanning Speed } \\
(\mathbf{m m} / \mathbf{s})\end{array}$ & $\begin{array}{c}\text { Beam Offset } \\
(\mathbf{m m})\end{array}$ & Build Angle \\
\hline 1 & 270 & 900 & 0.02 & 0 \\
\hline 2 & 270 & 1300 & 0.04 & 30 \\
\hline 3 & 270 & 1600 & 0.06 & 45 \\
\hline 4 & 330 & 900 & 0.04 & 45 \\
\hline 5 & 330 & 1300 & 0.06 & 0 \\
\hline 6 & 330 & 1600 & 0.02 & 30 \\
\hline 7 & 370 & 900 & 0.06 & 30 \\
\hline 8 & 370 & 1300 & 0.02 & 45 \\
\hline 9 & 370 & 1600 & 0.04 & 0 \\
\hline
\end{tabular}

Tab. 2. Process parameter sets designed according to Taguchi's L9 orthogonal array and calculated heat input values.

EOSH M290 device was used for direct metal laser sintering (DMLS) method. Hatch distance is $0.19 \mathrm{~mm}$ and layer thickness is $0.03 \mathrm{~mm}$ defined as constant parameters. After the samples were manufactured, support structures were cleaned manually and excessive powders were removed by sand blasting. Three repeated samples were used for dimensional measurements which were taken by Hexagon 100907 CMM delicately in accordance with related standard (ISO 14253-1:2017). Manufactured parts on the build plate and measurement procedure and measured dimensions on the samples were shown in Fig. 2. and in Fig.3 respectively.

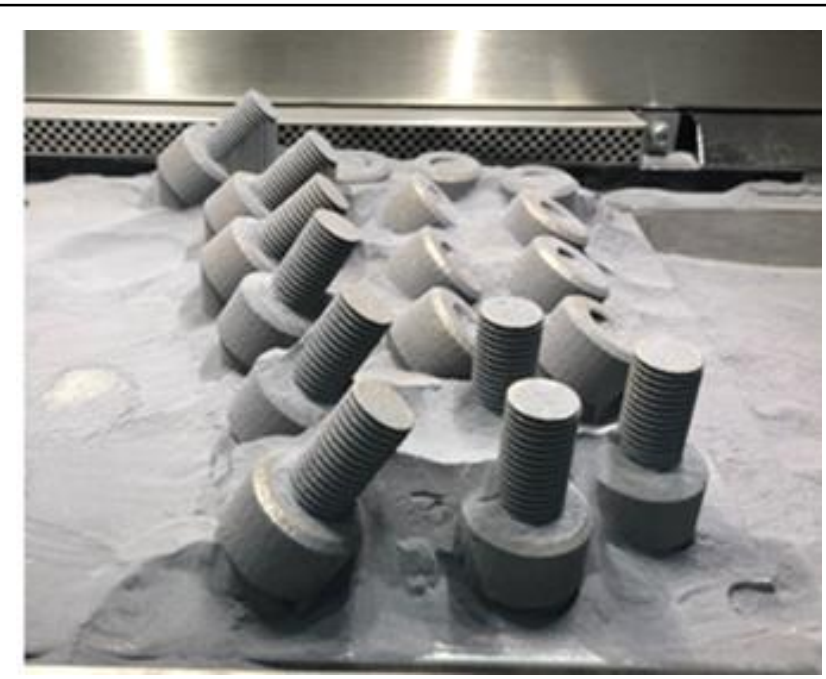

Fig. 2. Screw samples on the build plate just after manufacturing process. 

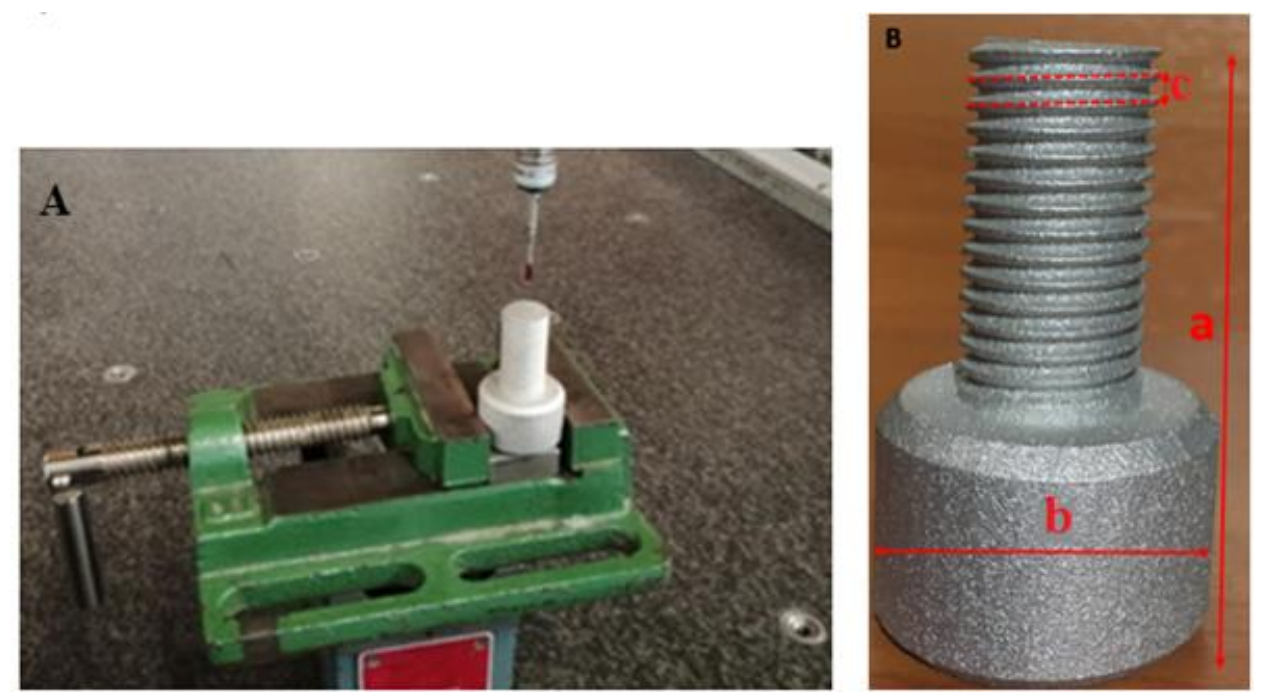

Fig. 3. a) CMM measurement, b) Measured dimensions of the samples

\section{Results and Discussions}

Dimensional measurement results and calculated deviations were reported in Tab. 3 where the nominal values were also given at the bottom of the table.

\begin{tabular}{|c|c|c|c|c|c|c|}
\hline & \multicolumn{7}{|c|}{ Measurements (mm) } \\
\hline Sample No & A & Dev-A & B & Dev-B & C & Dev-C \\
\hline $\mathbf{1}$ & 50.24 & 0.24 & 29.78 & 0.22 & 2.12 & 0.12 \\
\hline $\mathbf{2}$ & 50.15 & 0.15 & 29.78 & 0.22 & 2.42 & 0.42 \\
\hline $\mathbf{3}$ & 49.90 & 0.10 & 29.68 & 0.32 & 1.93 & 0.07 \\
\hline $\mathbf{4}$ & 50.09 & 0.09 & 29.71 & 0.29 & 2.16 & 0.16 \\
\hline $\mathbf{5}$ & 50.18 & 0.18 & 29.80 & 0.20 & 2.18 & 0.18 \\
\hline $\mathbf{6}$ & 50.09 & 0.09 & 29.71 & 0.29 & 2.16 & 0.16 \\
\hline $\mathbf{7}$ & 50.21 & 0.21 & 29.74 & 0.26 & 1.94 & 0.06 \\
\hline $\mathbf{8}$ & 50.04 & 0.04 & 29.80 & 0.20 & 2.01 & 0.01 \\
\hline $\mathbf{9}$ & 50.03 & 0.03 & 29.79 & 0.21 & 1.85 & 0.15 \\
\hline Nominal value (mm) & \multicolumn{7}{|c|}{50} & 30 & & 2 \\
\hline
\end{tabular}

Tab. 3. Measurement results and deviations of screw parts

Dimensional measurements with CMM was compared with technical drawing dimensions which defined as nominal value. The difference between these two values were calculated and recorded as amount of deviation.

Deviation $=$ Nominal Value - Measured Value

Deviation amounts of samples were analysed Taguchi Analysis method by MiniTab 17, using smaller is better option in signal to noise table. Investigation for dimension A, deviations were changed the range of $0.03 \mathrm{~mm}$, which was Sample 9, to 0.24 , which is Sample 1, in Fig. 4. 
Scanning speed is significant parameter for part length. When the scanning speed increases from 900 to $1600 \mathrm{~mm} / \mathrm{s}$, Dev-A value decreases significantly. Another parameter to be mentioned is laser power. Laser power affects samples like scanning speed. When the laser power increases from 270 to $370 \mathrm{~W}$, Dev-A value decreases again. Thus, it could be concluded that increasing of scanning speed and laser power provides better dimensional accuracy. The optimum process parameters for A dimension is $370 \mathrm{~W}$ laser power, $1600 \mathrm{~mm} / \mathrm{s}$ scanning speed, $0.04 \mathrm{~mm}$ beam offset and $45^{\circ}$ build angle.

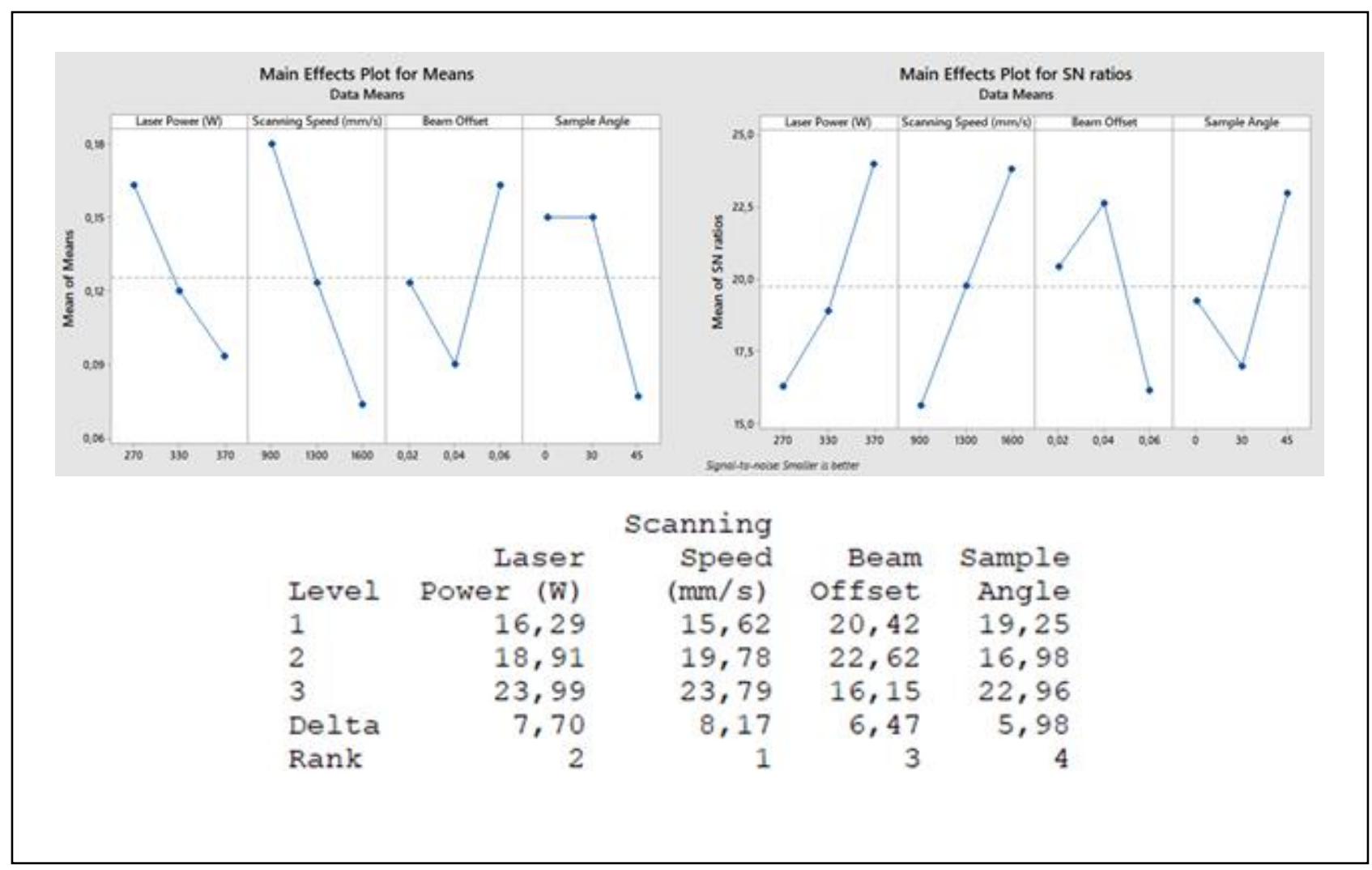

Fig. 4. Taguchi Analysis for measurement of A dimension

Analysis results for dimension B revealed that scanning speed is an important parameter. It is should be noticed that increasing the scanning speed did not linearly affect dimensional accuracy. While the scanning speed was $1300 \mathrm{~mm} / \mathrm{s}$, lower deviation values were measured. The average deviation in this scan speed is reported as $0.20 \mathrm{~mm}$. However, the maximum deviation was reported as $0.27 \mathrm{~mm}$ when the scan speed was $1600 \mathrm{~mm} / \mathrm{s}$.

Also, the build angle cannot be ignored during the manufacturing process. Taguchi analysis of measurements B shown that, minimum deviation value was $0.20 \mathrm{~mm}$ at 0 and 45 degrees. However, minimum average deviation reported as $0.21 \mathrm{~mm}$ at 0 degree. Where the dimensional deviations average were measured maximum at 45 degree. In addition, average of 30 degree was $0.25 \mathrm{~mm}$. Dimensional accuracy decreases with increasing build angle. The optimum process parameters for $\mathrm{B}$ dimension is $370 \mathrm{~W}$ laser power, $1300 \mathrm{~mm} / \mathrm{s}$ scanning speed, $0.02 \mathrm{~mm}$ beam offset and $0^{\circ}$ build angle. 


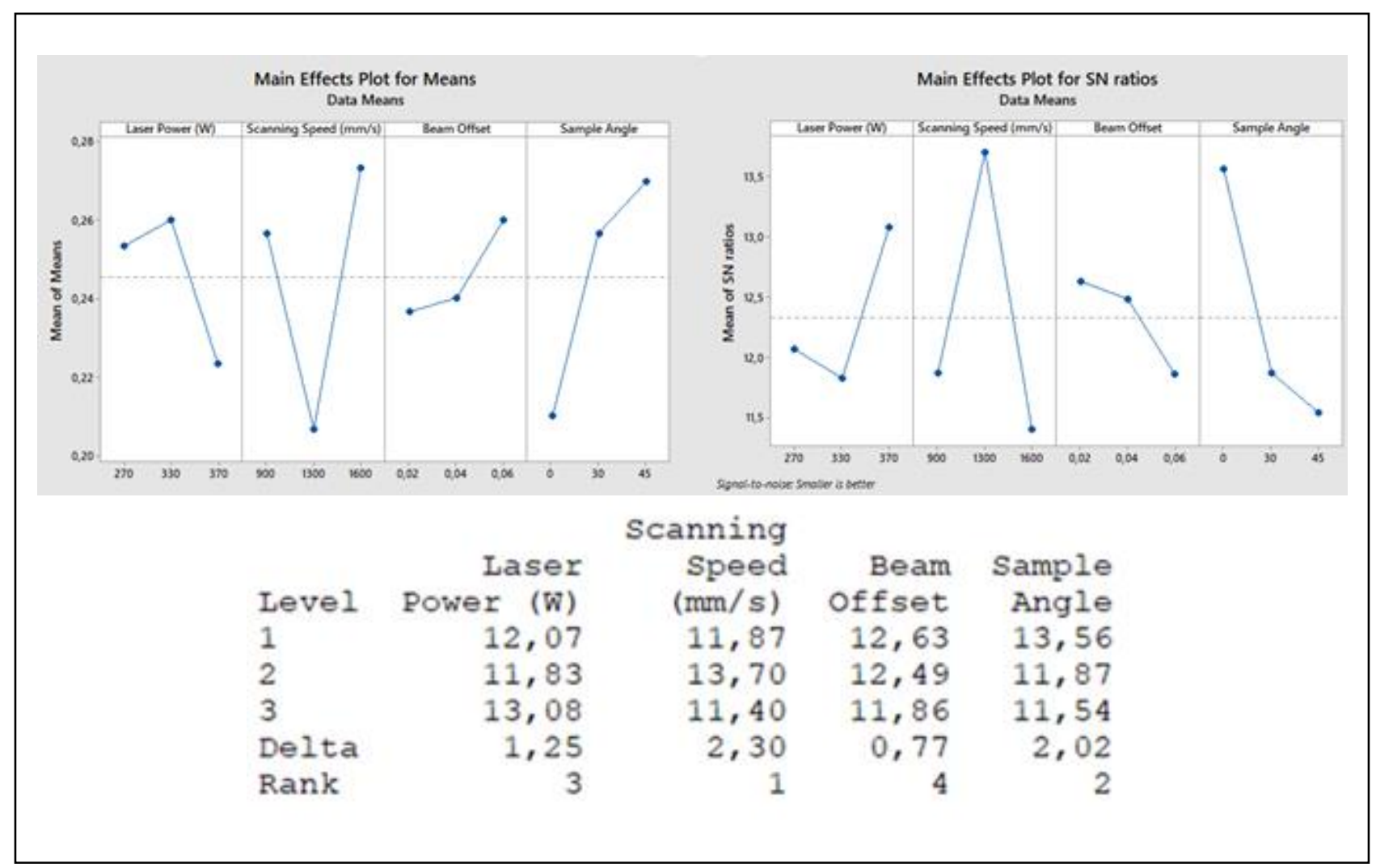

Fig. 5. Taguchi Analysis for measurement of B dimension

For teeth dimension which is named as $\mathrm{C}$, according to the analysis results, it was revealed that beam offset is the key parameter. The lowest deviation among in the total results is Sample 9, which was measured as $0.01 \mathrm{~mm}$ and produced with a $0.06 \mathrm{~mm}$ offset. According to the analysis results, the parts produced with a $0.02 \mathrm{~mm}$ set have the lowest deviation. However, it should be noted that the deviations of samples produced with $0.06 \mathrm{~mm}$ offset and $0.02 \mathrm{~mm}$ offset are relatively equal, $0.09 \mathrm{~mm}$ with $0.02 \mathrm{~mm}$ offset and 0.10 with $0.06 \mathrm{~mm}$ offset, when compared with their mean values. Maximum deviation results was measured with $0.04 \mathrm{~mm}$ offset degrees.

Other important parameter was reported as laser power. Reported average values are, $0.07 \mathrm{~mm}$ with $370 \mathrm{~mm} / \mathrm{s}$ scanning speed, $0.16 \mathrm{~mm}$ with $330 \mathrm{~mm} / \mathrm{s}$ scanning speed and $0.20 \mathrm{~mm}$ with $270 \mathrm{~mm} / \mathrm{s}$ scanning speed. It's possible to say that dimensional accuracy increases with increasing scanning speed, according to analysis results in Fig 6. The optimum process parameters for $\mathrm{C}$ dimension is $370 \mathrm{~W}$ laser power, $1300 \mathrm{~mm} / \mathrm{s}$ scanning speed, $0.02 \mathrm{~mm}$ beam offset and $45^{\circ}$ build angle.

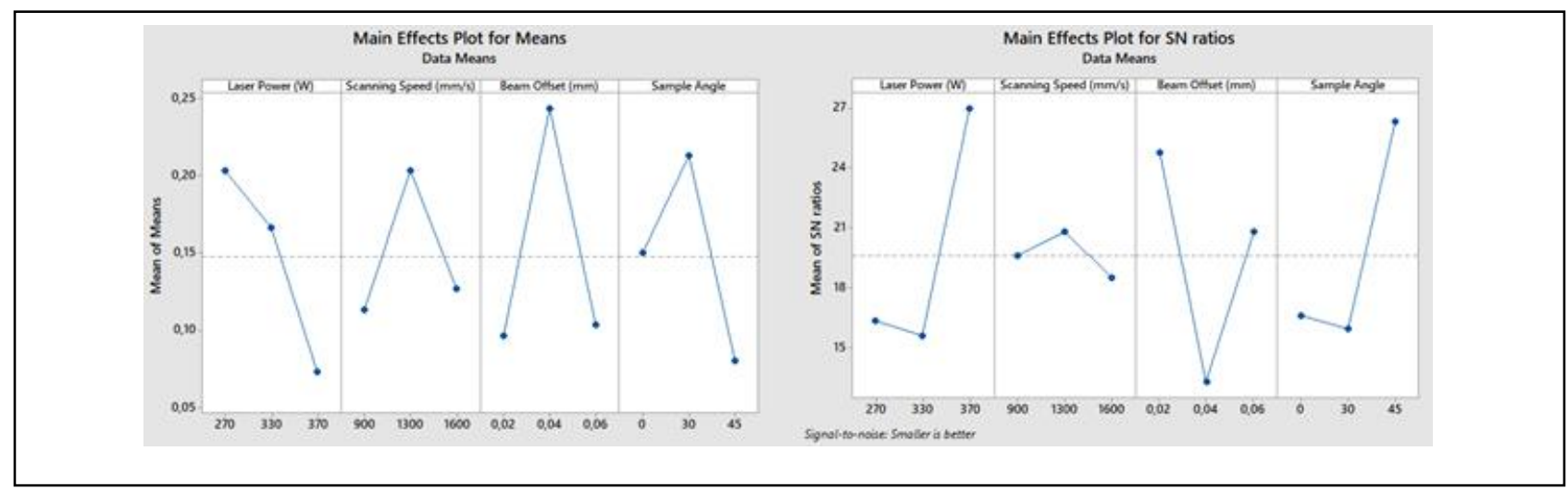


Bagci, H. B.; Sagbas, B. \& Durakbasa, N.: Effect of Direct Metal Laser Sintering P...

\begin{tabular}{|c|c|c|c|c|}
\hline & & Scanning & Beam & \\
\hline Level & $\begin{array}{r}\text { Laser } \\
\text { ower (W) }\end{array}$ & $\begin{array}{l}\text { Speed } \\
(\mathrm{mm} / \mathrm{s})\end{array}$ & $\begin{array}{r}\text { Offset } \\
(\mathrm{mm})\end{array}$ & $\begin{array}{r}\text { Sample } \\
\text { Angle }\end{array}$ \\
\hline 1 & 16,35 & 19,59 & 24,78 & 16,60 \\
\hline 2 & 15,58 & 20,81 & 13,31 & 15,96 \\
\hline 3 & 26,97 & 18,50 & 20,81 & 26,34 \\
\hline Delta & 11,40 & 2,31 & 11,47 & 10,38 \\
\hline Rank & 2 & 4 & 1 & \\
\hline
\end{tabular}

Fig. 6. Taguchi Analysis for measurement of $\mathrm{C}$ dimension

\begin{tabular}{|l|l|l|l|l|}
\cline { 3 - 5 } \multicolumn{2}{c|}{} & \multicolumn{3}{c|}{ F-Value } \\
\hline Source & DF & A & B & C \\
\hline Laser Power & 2 & 116,32 & 46,65 & 383,18 \\
\hline Scan Speed & 2 & 248,92 & 168,76 & 215,61 \\
\hline Beam Offset & 2 & 122,92 & 24,76 & 545,39 \\
\hline Build Angle & 2 & 169,48 & 118,29 & 405,25 \\
\hline $\begin{array}{l}\text { Error } \\
\text { Total }\end{array}$ & \multicolumn{4}{|l}{} \\
\cline { 1 - 5 }
\end{tabular}

Tab. 4. Analysis of Variance Table

Statistical significance of parameters were determined by analysis of variance (ANOVA). The analysis results were reported in table 5. The table value of the $\mathrm{F}$ was read as $0,05(2,18)=3.55$ for degree of freedom (DF) for experiment factors 2 and for error was 18. The calculated $F$ values are higher than $F_{\text {table }}$ that means all of the factors have significant effect on the dimensional properties of the DMLS manufactured parts. Results and analysis revealed that the process parameters affect the dimensional accuracy differently depending on the direction. Dimension A expressing the deviations in the $\mathrm{Z}$ direction and dimension $\mathrm{B}$ expressing the radial deviation showed deviations at different rates in the same parameter sets. This can be explained by the anisotropic properties of parts produced by additive manufacturing.

\section{Conclusion}

In this study, the effect of process parameters on dimensional accuracy of DMLSed AlSi10Mg parts was investigated with different parameter sets generated by Taguchi's L9 orthogonal experimental design model. Laser power, scanning speed, beam offset and sample angle were applied at three different levels. It can be concluded that,

- Laser power, scanning speed, beam offset and sample angle parameters effects dimensional accuracy of DMLS produced AlSi10Mg parts. Scanning speed is a important parameter for linear dimensions. While manufacturing DMLS parts, it is possible to reduce dimensional errors with scanning speed.

- Teeth geometry have been mostly effected by beam offset parameter. Moreover, samples produced with $0.04 \mathrm{~mm}$ offset gave the best dimensional results. The 
defined optimal conditions for the distance between two teeth was the same as $9^{\text {th }}$ parameter set in which deviation was at the minimum value. So, the results were in accordance to each other which confirms that defined optimum parameter set is sensible.

- For optimization studies, it is important to make studies with different parameters to manufacture parts with the best dimensional accuracy and surface quality.

- This study continues with different parameter sets, verification experiments and statistical analysis. Moreover, surface properties will be examined in ongoing studies.

\section{Acknowledgement}

This work was supported by Yildiz Technical University Scientific Research Projects Coordination Unit. Project Number: FYL-2019-3699

\section{References}

Bhardwaj, T., \& Shukla, M. (2018). Direct metal laser sintering of maraging steel: effect of building orientation on surface roughness and microhardness. Materials Today: Proceedings, 5(9), 20485-20491.

Bhardwaj, T., \& Shukla, M. (2018). Effect of laser scanning strategies on texture, physical and mechanical properties of laser sintered maraging steel. Materials Science and Engineering: A, 734, 102-109.

Gajera, H. M., Dave, K. G., Darji, V. P., \& Abhishek, K. (2019). Optimization of process parameters of direct metal laser sintering process using fuzzy-based desirability function approach. Journal of the Brazilian Society of Mechanical Sciences and Engineering, 41(3), 124.

Ghani, S. A. C., Zakaria, M. H., Harun, W. S. W., \& Zaulkafilai, Z. (2017). Dimensional accuracy of internal cooling channel made by selective laser melting (SLM) And direct metal laser sintering (DMLS) processes in fabrication of internally cooled cutting tools. In MATEC Web of Conferences (Vol. 90, p. 01058). EDP Sciences.

Han, X., Zhu, H., Nie, X., Wang, G., \& Zeng, X. (2018). Investigation on selective laser melting AlSi10Mg cellular lattice strut: molten pool morphology, surface roughness and dimensional accuracy. Materials, 11(3), 392.

Hanzl, P., Zetkova, I., \& Dana, M. (2017, January). A comparison of lattice structures in metal additive manufacturing. In Proceedings of the 28th DAAAM International Symposium (pp. 0481-0485).

ISO 14253-1:2017 Geometrical product specifications (GPS) - Inspection by measurement of workpieces and measuring equipment - Part 1: Decision rules for verifying conformity or nonconformity with specifications

Jhavar, S., \& Jain, N. (2014). Development of micro-plasma wire deposition process for layered manufacturing. Daaam international scientific book, 20, 239-256.

Maamoun, A. H., Xue, Y. F., Elbestawi, M. A., \& Veldhuis, S. C. (2018). Effect of selective laser melting process parameters on the quality of al alloy parts: Powder 
Bagci, H. B.; Sagbas, B. \& Durakbasa, N.: Effect of Direct Metal Laser Sintering P... characterization, density, surface roughness, and dimensional accuracy. Materials, 11(12), 2343.

Majeed, A., Ahmed, A., Salam, A., \& Sheikh, M. Z. (2019). Surface quality improvement by parameters analysis, optimization and heat treatment of AlSi10Mg parts manufactured by SLM additive manufacturing. International Journal of Lightweight Materials and Manufacture, 2(4), 288-295.

Mohammadi, M., \& Asgari, H. (2018). Achieving low surface roughness AlSi10Mg_200C parts using direct metal laser sintering. Additive Manufacturing, 20, 23-32.

Rautio, T., Mäkikangas, J., Mustakangas, A., \& Mäntyjärvi, K. (2019). Disk Laser Assisted Surface Heat Treatments Of AlSi10Mg Parts Produced By Selective Laser Melting (SLM). Procedia Manufacturing, 36, 95-100.

Sağbaş, B . (2020). Effect of Orientation Angle on Surface Quality and Dimensional Accuracy of Functional Parts Manufactured by Multi Jet Fusion Technology. European Mechanical Science , 4 (2), 47-52.

Sagbas, B. (2020). Post-processing effects on surface properties of direct metal laser sintered AlSi10Mg parts. Metals and Materials International, 26(1), 143-153.

Sing, S. L., Wiria, F. E., \& Yeong, W. Y. (2018). Selective laser melting of lattice structures: A statistical approach to manufacturability and mechanical behavior. Robotics and Computer-Integrated Manufacturing, 49, 170-180. 